\title{
A meta-analysis of hypoxia inducible factor 1-alpha (HIF1A) gene polymorphisms: association with cancers
}

\author{
Md. T Anam ${ }^{1}$, Alokta Ishika², Md. B Hossain ${ }^{1}$ and Jesmin ${ }^{2 *}$
}

\begin{abstract}
Background: Hypoxia inducible factor 1-alpha (HIF1A) is a transcription factor that plays important role in regulating cascade of reactions. In this study, the effect of rs11549465 (1772 C/T) and rs11549467 (1790 G/A) polymorphisms of HIF1A gene and its association with cancers were investigated through meta-analysis.
\end{abstract}

Methods: Meta-analysis of genome wide association studies of HIF1A $1772 \mathrm{C} / T$ polymorphism were conducted on 22 case-control studies of sample size 19024 and for $1790 \mathrm{G} / \mathrm{A}$ polymorphism 19 case-control studies were included with sample size 10654. Genotype and allelic frequency compared between cases and controls together with further subgroup analyses were carried out by cancer type and ethnicity.

Results: Meta-analysis from this study indicated that HIF1A $1772 \mathrm{C} / \mathrm{T}$ polymorphism is significantly associated with overall cancer risk. T allele and genotype $\Pi$ are significantly associated with increasing overall cancer risk; odds ratios (OR) dominant model [T + CT vs. CC: OR 1.30, $95 \%$ Cl (1.06-1.59), p-value: 0.0115], and T allele vs. C allele: OR 1.32, $95 \% \mathrm{Cl}$ (1.07-1.63), p-value: 0.0098. Also, HIF1A $1790 \mathrm{G} / \mathrm{A}$ polymorphism, analyses showed that A allele and genotype AA are significantly associated with increasing overall cancer risk; odds ratios (OR) homozygote comparison [AA vs. GG: OR 5.10, $95 \%$ Cl (3.12-8.33), p-value: <0.0001], heterozygote comparison [GA vs. GG: OR 1.74, $95 \%$ Cl (1.20-2.52), p-value: 0.0033], dominant model [AA + GA vs. GG: OR 1.82, $95 \%$ Cl (1.26-2.62), p-value: 0.0014], recessive model [AA vs. GA + GG: OR 3.79, $95 \%$ Cl (2.34-6.15), $p$-value: <0.0001] and A allele vs. G allele: OR 1.82, $95 \% \mathrm{Cl}(1.31-2.52)$, $p$-value: 0.0003.

Conclusion: In detail meta-analysis indicated that both the polymorphisms $1772 \mathrm{C} / \mathrm{T}$ and $1790 \mathrm{G} / \mathrm{A}$ are significantly associated with overall cancer risk. The subgroup analyses showed that lung cancer is significantly associated with both polymorphisms. Although the $1772 \mathrm{C} / T$ polymorphism is significantly associated with decreasing risk of renal cell carcinoma but the $1790 \mathrm{G} / \mathrm{A}$ polymorphism has shown to significantly increase the cancer risk in both Caucasian and Asian population. Thus, HIF1A could be a useful prognostic marker for cancers early predisposition.

Keywords: HIF1A, Genome wide association studies, Cancer, Meta-analysis

\section{Background}

Cancer is the second leading cause of morbidity and mortality worldwide [1]. One major feature of cancer is uncontrolled cell proliferation, which can then invade adjacent parts of the body and spread to other organs, the latter process is referred as metastases, which are the major cause of death from cancer [2]. The most common

\footnotetext{
*Correspondence: jesmin@du.ac.bd

2Department of Genetic Engineering \& Biotechnology, University of Dhaka, Dhaka 1000, Bangladesh

Full list of author information is available at the end of the article
}

causes of cancer deaths are due to cancers of the: lung (1.59 million deaths), liver (745,000 deaths), stomach (723,000 deaths), colorectal (694,000 deaths), breast (521,000 deaths) and esophageal (400,000 deaths) [1, 2]. Alongside, metabolic alterations and tumor hypoxia have consistently been identified as classical features with aggressive malignancy [3, 4]. Hypoxia regulates tumor cell phenotype mainly by altering genes that are sensitive to oxygen pressure [5]. However, the exact mechanism of carcinogenesis is yet to be elucidated. In recent years, an increasing number of studies have focused on 
understanding the relationship between genetic factors and cancer risk $[3,4]$. Through the years, it has become well accepted that single nucleotide polymorphisms (SNPs) are the most common and effective type of genetic variations studied in association with disease susceptibility and are the markers of many complex diseases [6].

Hypoxia inducible factor $1 \alpha$ (HIF1A), is a transcription factor that has major impacts in the process of development and progression of cancers [7]. HIF1A regulates the expression of over 100 genes that control the major cellular functions including apoptosis, cell proliferation, glucose metabolism, erythropoiesis, iron metabolism and angiogenesis. It is a master regulator of oxygen homeostasis [7]. In the scientific community, HIF1A has been a research focus and a number of SNPs within HIF1A gene have been identified in association with cancers, with the most widely studied polymorphisms are C1772T (rs11549465) and G1790A (rs11549467) polymorphisms [8-38]. These two SNPs are located within the same domain (ODD/ pVHL) in exon 12 of the HIF1A gene $[8,9]$. Recently a meta-analysis has revealed that $\mathrm{C} 1772 \mathrm{~T}$ is not in substantial linkage disequilibrium (LD) with G1790A [38]. A number of studies have suggested that these two nonsynonymous mutations might alter the transcriptional activity of HIF1A gene by causing structural changes with varied stability, which in turn, might influence the downstream target genes expression and regulation $[8,9,38]$. In the recent years, a good number of studies have investigated the impact of HIF1A polymorphisms on cancer risk in different populations; however reported results varied across studies and remain inconclusive [10-38]. In this study, the effect of rs11549465 (1772 C/T) and rs11549467 (1790 G/A) polymorphisms of HIF1A gene and its association with cancers were investigated systematically through metaanalysis.

\section{Methods}

\section{Search study and study selection}

The PubMed, PubMed Central and Google Scholar databases were searched systematically to retrieve compatible and pertinent peer reviewed publications of empirical studies. Published articles of last 15 years (ended on December 2014), in English language were only considered for this study. The search terms included were (1) HIF1A, (2) GWAS, (3) SNPs, (4) polymorphisms, (5) C1772T/ P582S, (6) A1790G/ A588T, (7) case-control study, and (8) cancer.

\section{Eligibility criteria}

Two authors independently investigated titles and abstracts of all the articles. Irrelevant and incompatible studies were excluded primarily. For final review, criteria's for further study elimination were: if (1) the study population was not defined completely; (2) it is not a case-control study; (3) not a genome wide association study; (4) incomplete information of allele frequency; and (5) the year of study conducted was not specified. Also, reviews, editorials, meta-analysis and non-human researches were excluded. Only case-control studies, genome wide association study (GWAS) and human researches were considered for the final review. Further, the references of the selected studies were screened carefully for incorporation of additional relevant studies. Only English language articles were considered for this study. Discrepancies and difficulties were discussed with corresponding authors where necessary. Following information were extracted from each study: (1) authors name, (2) year of study, (3) ethnicity of the study subjects, (4) cancer type and (5) allelic frequency (Fig. 1).

\section{Meta-analysis}

For HIF1A $1772 \mathrm{C} / \mathrm{T}$ polymorphism 22 case-control studies were included of sample size 19024 and for 1790 G/A polymorphism 19 case-control studies were included with sample size 10654. The meta-analysis was prepared in accordance with PRISMA statement [39].

\section{Statistical analysis}

Meta-analysis of genome wide association studies (GWAS) of HIF1A were conducted for two polymorphisms, $1772 \mathrm{C} / \mathrm{T}$ and $1790 \mathrm{G} / \mathrm{A}$ using odds ratios (ORs). A slightly amended estimator of OR was used to avoid the computation of reciprocal of zeros among observed values in the calculation of the original OR [40]. Pooled ORs with $95 \%$ CIs were calculated using random effects model (REM) incorporating the inverse variance weighted method [41]. Heterogeneity among studies was assessed using the Q statistic [42] and quantified using $\mathrm{I}^{\wedge} 2$ index [43]. Subgroup analyses were carried out by cancer type and ethnicity. The Hardy Weinberg Equilibrium (HWE) test was performed for the controls of each study. The studies with control not in HWE were supervised for sensitivity analysis. Publication bias was assessed visually by conventionally constructed funnel plot where the inverse of the standard error $(1 / \mathrm{se})$ of the effect estimates were plotted against the logarithm transformation of Odds Ratios [log(OR)] [44]. Furthermore, Egger's test was performed to provide quantitative evidence of publication bias [45]. "Gap: Genetic analysis package" was used to perform the Hardy Weinberg Equilibrium (HWE) test $[46,47]$. All analyses were conducted using "meta" package in R environment [46].

\section{Summary measures}

Odds Ratios (OR) with a $95 \%$ confidence interval (CI) were calculated to evaluate the genotype contrasts. The genotype contrasts for the HIF1A $1772 \mathrm{C} / \mathrm{T}$ polymorphisms were: homozygote comparison [TT versus $\mathrm{CC}$ ], 


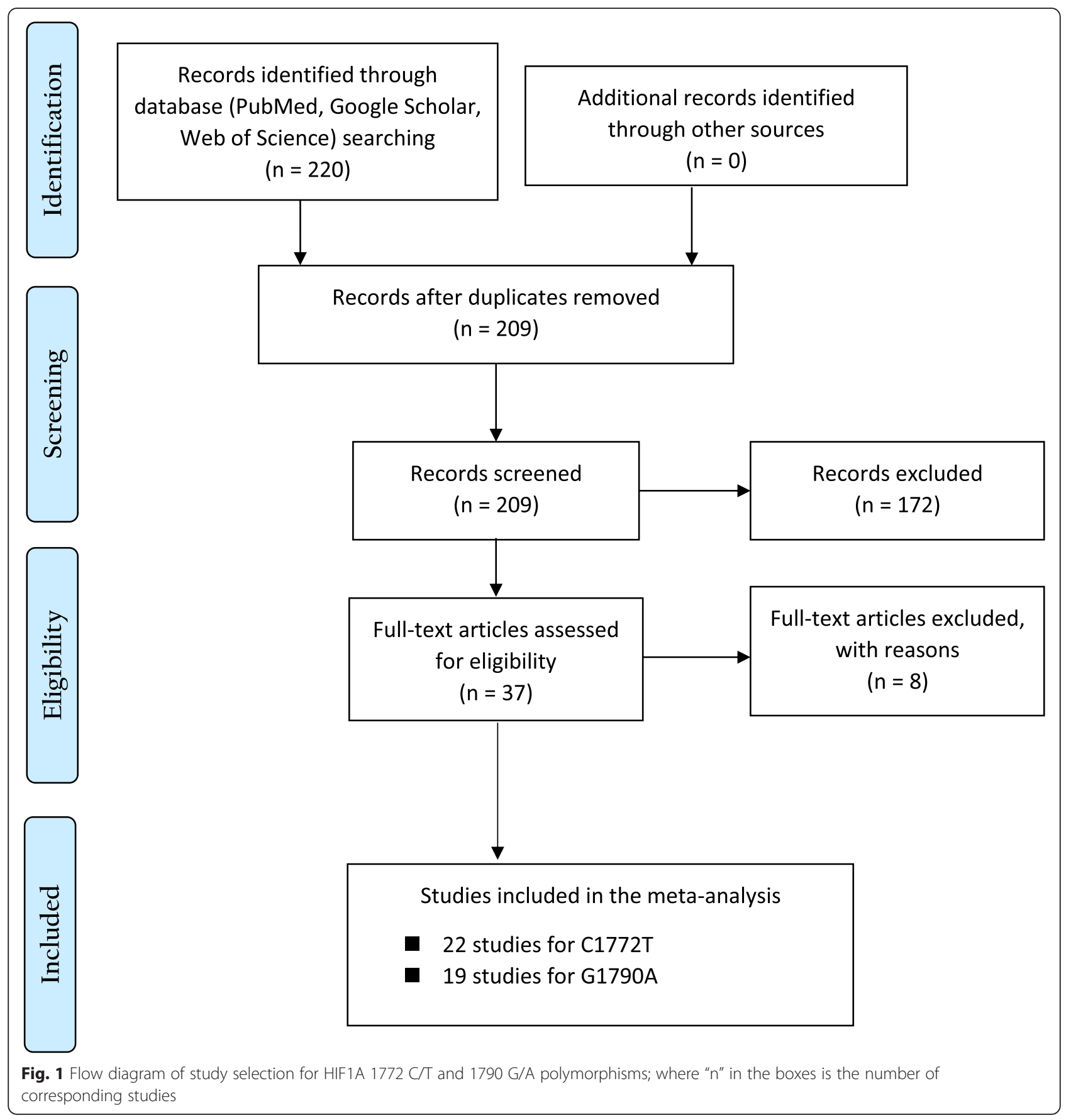

heterozygote comparison [CT versus $\mathrm{CC}$ ], and dominant model $[\mathrm{TT}+\mathrm{CT}$ versus $\mathrm{CC}]$, recessive model [TT versus $\mathrm{CT}+\mathrm{CC}]$ and T allele versus C allele. For HIF1A $1772 \mathrm{C} /$ $\mathrm{T}$ polymorphism, three studies were found with genotype information of CC and CT + TT. These three studies were included only to evaluate genotype contrast of dominant model [TT + CT vs. CC]. The genotype contrasts for the HIF1A 1790 G/A polymorphism were: homozygote comparison [AA versus GG], heterozygote comparison [GA versus GG] and dominant model [AA + GA versus GG], recessive model $[A A$ versus $G A+G G]$ and $[G$ versus $A$ allele].

\section{Results and discussion}

Study characteristics

In the meta-analysis of the HIF1A $1772 \mathrm{C} / \mathrm{T}$ polymorphism, ten different types of cancers consisted of 22 studies with 8149 cancer cases and 10,875 controls were included. 
The types of cancer included in these studies were prostate cancer, colorectal cancer, renal cell carcinoma, breast cancer, lung cancer, oral squamous cell carcinoma (OSCC), head-neck cancer, cervical cancer, bladder carcinoma and pancreatic cancer. For the following cancer types: head-neck, cervical, bladder and pancreatic only one study of each were found for the final review. So, these cancer types with single studies were incorporated in subgroup analysis as Other Cancers (Table 1).

For the meta-analysis of HIF1A 1790 G/A polymorphism, 19 studies with eleven different cancer types consisted of 4681 cancer cases and 5973 controls were included. The cancer types associated with this polymorphism were: renal cancer, prostate cancer, breast cancer, lung cancer, oral squamous cell carcinoma (OSCC), head-neck cancer, gastric cancer, hepatocellular carcinoma, lymph node metastasis, pancreatic cancer and colorectal cancer. For final review, only one study of each of the following cancer types was found: head-neck cancer, gastric cancer, hepatocellular carcinoma, lymph node metastasis, pancreatic cancer and colorectal cancer. These cancer types with single studies were incorporated in subgroup analysis as Other Cancers (Table 2).

\section{Association of the HIF1A 1772 C/T polymorphism with cancer risk}

The pooled ORs for overall cancer suggested that the HIF1A $1772 \mathrm{C} / \mathrm{T}$ polymorphism was significantly associated with increasing cancer risk for the dominant model [TT + CT vs. CC: OR 1.30, 95 \% CI (1.06-1.59), $p$-value: 0.0115 ] and [T vs. C allele: OR 1.32, 95 \% CI (1.07-1.63), p-value: 0.0098] (Fig. 2).

\section{Subgroup analyses performed by cancer type}

The subgroup analyses of prostate cancer, colorectal cancer, breast cancer and oral squamous-cell carcinoma suggested no significant association of the HIF1A 1772 C/T polymorphism. However, the subgroup analyses of renal cell carcinoma suggested that the HIF1A $1772 \mathrm{C} / \mathrm{T}$ polymorphism is significantly associated with lowering renal cell carcinoma risk in homozygote comparison [TT vs. CC: OR 0.27, 95 \% CI (0.08-0.90), p-value:0.0335]. Interestingly, the results of subgroup analyses of lung cancer suggested that the HIF1A $1772 \mathrm{C} / \mathrm{T}$ polymorphism is highly associated with increasing lung cancer risk in homozygote comparison [TT vs. CC: OR 4.88, 95 \% CI (2.42-9.84), $p$-value: $<0.0001$, recessive model [TT vs. CT + CC: OR 4.04, 95 \% CI $(2.02-8.08), p$-value: $<0.0001]$.

Table 1 Characteristic of eligible studies included in meta-analysis of HIF1A 1772 C/T polymorphism

\begin{tabular}{|c|c|c|c|c|c|c|}
\hline Study & Year & Country & Ethnicity & Cancer & Case/Control & HWE \\
\hline Clifford et al. [8] & 2001 & UK & Caucasian & Renal cell carcinoma & $35 / 143$ & $0.018(\mathrm{~N})$ \\
\hline Tanimoto et al. [9] & 2003 & Japanese & Asian & Head-neck cancer & $55 / 110$ & $0.545(Y)$ \\
\hline Ollerenshawa et al. [10] & 2004 & European & Caucasian & Renal cell carcinoma & $160 / 162$ & $<0.001(\mathrm{~N})$ \\
\hline Chau et al. [11] & 2005 & USA & Mixed & Prostate cancer & 196/196 & $<0.001(\mathrm{~N})$ \\
\hline Franse et al. [12] & 2006 & Swedish & Caucasian & Colorectal cancer & $198 / 258$ & $0.916(Y)$ \\
\hline Konac et al. [13] & 2007 & Turkish & Caucasian & Cervical cancer & $32 / 107$ & $0.229(Y)$ \\
\hline Li et al. [14] & 2007 & American & Mixed & Prostate cancer & $1041 / 1234$ & $0.159(Y)$ \\
\hline Lee et al. [15] & 2008 & Korean & Asian & Breast cancer & $1332 / 1369$ & $0.250(Y)$ \\
\hline Kim et al. [16] & 2008 & Korean & Asian & Breast cancer & $90 / 102$ & $0.641(Y)$ \\
\hline Nadaoka et al. ${ }^{a}[17]$ & 2008 & Japanese & Asian & Transitional cell carcinoma of bladder & $219 / 461$ & \\
\hline Jacobs et al. [18] & 2008 & American & Mixed & Prostate cancer & $1420 / 1450$ & $0.041(\mathrm{~N})$ \\
\hline Foley et al. [19] & 2009 & Ireland & Caucasian & Prostate cancer & $95 / 188$ & $0.623(Y)$ \\
\hline Morris et al. [20] & 2009 & Polish & Caucasian & Renal cell carcinoma & $332 / 313$ & $0.083(Y)$ \\
\hline Chen et al. [21] & 2009 & Taiwanese & Asian & Oral squamous cell carcinoma (OSCC) & $174 / 347$ & $0.722(Y)$ \\
\hline Shieh et al. [22] & 2010 & Taiwan & Asian & Oral squamous cell carcinoma (OSCC) & $305 / 96$ & $0.710(Y)$ \\
\hline Knechtel et al. ${ }^{a}$ [23] & 2010 & Austria & Caucasian & Colorectal cancer & $368 / 2156$ & \\
\hline Kang et al. ${ }^{a}[24]$ & 2011 & Korean & Asian & Colorectal cancer & $50 / 50$ & \\
\hline Putra et al. [25] & 2011 & Japanese & Asian & Lung cancer & $83 / 110$ & $0.545(Y)$ \\
\hline Wang et al. [26] & 2011 & Chinese & Asian & Pancreatic cancer & $263 / 271$ & $0.352(Y)$ \\
\hline Kuo et al. [27] & 2012 & Taiwanese & Asian & Lung cancer & $285 / 300$ & $0.132(Y)$ \\
\hline Li et al. [28] & 2012 & China & Asian & Prostate cancer & $662 / 716$ & $0.267(Y)$ \\
\hline Fraga et al. [29] & 2014 & Portuguese & Caucasian & Prostate cancer & $754 / 736$ & $0.400(Y)$ \\
\hline
\end{tabular}

${ }^{a}$ Frequency of genotypes " $\mathrm{CT}+\Pi$ ". HWE Hardy-Weinberg Equilibrium 
Table 2 Characteristic of eligible studies included in meta-analysis of HIF1A 1790G/A polymorphism

\begin{tabular}{|c|c|c|c|c|c|c|}
\hline Study & Year & Country & Ethnicity & Cancer & Case/Control & HWE \\
\hline Clifford et al. [8] & 2001 & Caucasian & Caucasian & Renal cancer & $48 / 144$ & $0.866(Y)$ \\
\hline Tanimoto et al. [9] & 2003 & Japan & Asian & Head neck squeamish cell carcinoma & $55 / 110$ & $0.655(Y)$ \\
\hline Ollerenshaw et al. [10] & 2004 & Caucasian & Caucasian & Renal cancer & $146 / 288$ & $<0.001(\mathrm{~N})$ \\
\hline Fransen et al. [12] & 2006 & Sweden & Caucasian & Colorectal cancer & $198 / 256$ & $0.775(Y)$ \\
\hline Orr-Urtreger et al. [30] & 2007 & Israel & Caucasian & Prostate cancer & $200 / 300$ & $0.954(Y)$ \\
\hline Li et al. [14] & 2007 & USA & Mixed & Prostate cancer & $1066 / 1264$ & $0.810(Y)$ \\
\hline Apaydin et al. [31] & 2008 & Turkey & Caucasian & Breast cancer & 102/102 & $0.840(Y)$ \\
\hline Kim et al. [16] & 2008 & Korea & Asian & Breast cancer & $90 / 102$ & $0.06(Y)$ \\
\hline Muñoz et al. [32] & 2009 & Spain & Caucasian & Oral squamous cell carcinoma & $64 / 139$ & $0.693(Y)$ \\
\hline Chen et al. [21] & 2009 & Taiwanese & Asian & Oral squamous cell carcinoma & $174 / 347$ & $0.701(Y)$ \\
\hline Morris et al. [20] & 2009 & polish & Caucasian & Renal cancer & $325 / 309$ & $0.662(Y)$ \\
\hline Li K et al. [33] & 2009 & Tibetan & Asian & Gastric cancer & $87 / 106$ & $0.764(Y)$ \\
\hline Hsiao et al. [34] & 2010 & Taiwan & Asian & Hepatocellular carcinoma & $102 / 347$ & $0.701(Y)$ \\
\hline Putra et al. [25] & 2011 & Japan & Asian & Lung cancer & $83 / 110$ & $0.655(Y)$ \\
\hline Wang et al. [26] & 2011 & Japan & Asian & Pancreatic cancer & $263 / 271$ & $0.486(Y)$ \\
\hline Kuo et al. [27] & 2012 & China & Asian & Lung cancer & $285 / 300$ & $0.154(Y)$ \\
\hline Li et al. [28] & 2012 & China & Asian & Prostate cancer & $662 / 716$ & $0.554(Y)$ \\
\hline Mera-Mene et al. [35] & 2012 & Spain & Caucasian & Lymph node metastasis & $111 / 139$ & $0.693(Y)$ \\
\hline Qin et al. [36] & 2012 & Asian & Asian & Renal cancer & $620 / 623$ & $0.411(Y)$ \\
\hline
\end{tabular}

HWE Hardy-Weinberg Equilibrium

The subgroup analyses of Other Cancers suggested that the HIF1A $1772 \mathrm{C} / \mathrm{T}$ polymorphism is highly associated with increasing Other Cancer risk in homozygote comparison [TT vs. CC: OR 27.20, 95 \% CI (5.04-146.78), $p$ value: 0.0001$]$, heterozygote comparison [CT vs. CC: OR 2.16, $95 \%$ CI (1.46-3.18), $p$-value: 0.0056], dominant model [TT + CT vs. CC: OR 1.92, $95 \%$ CI (1.17-3.14), $p$ value: 0.0093 ], recessive model [TT vs. CT + CC: OR 17.5, $95 \%$ CI (3.49-87.70), $p$-value: 0.0005 ] and [T vs. $C$ allele: OR 2.42, $95 \%$ CI (1.55-3.77), $p$-value: <0.0001] (Table 3).

\section{Subgroup analyses by ethnicity group}

The analyses data for the HIF1A $1772 \mathrm{C} / \mathrm{T}$ polymorphism suggested that there was no significant effect on the Caucasian population. However, the subgroup analyses of the Asian population suggested that the HIF1A 1772 $\mathrm{C} / \mathrm{T}$ polymorphism was significantly associated with increasing cancer risk in homozygote comparison [TT vs. CC: OR 4.98, 95 \% CI (2.66-9.31), $p$-value: $<0.0001]$, heterozygote comparison [CT vs. CC: OR 1.30, $95 \% \mathrm{CI}$ (1.01-1.69), $p$-value: 0.0455$]$, dominant model [TT + CT vs. CC: OR 1.41, $95 \%$ CI (1.08-1.84), $p$-value: 0.0109], recessive model [TT vs. CT + CC: OR 4.28, $95 \%$ CI (2.31-7.95), $p$-value: $<0.0001]$ and [T vs. C allele: OR 1.43, 95 \% CI (1.07-1.90), $p$-value: 0.0156] (Table 3). The subgroup analyses of mixed ethnic groups suggested that there were no significant association between HIF1A $1772 \mathrm{C} / \mathrm{T}$ polymorphism and cancer risk (Table 3).

\section{Sources of heterogeneity}

There were significant heterogeneity observed in the analyses of HIF1A $1772 \mathrm{C} / \mathrm{T}$ polymorphism for overall cancer heterozygote comparison [CT vs. $\mathrm{CC}$ : $\mathrm{Q}=69.67$, d.f $=18$, $p$-value $\left.0.0001, \mathrm{I}^{\wedge} 2=74.2 \%(59.5 \%-83.5 \%)\right]$, dominant model $[\mathrm{TT}+\mathrm{CT}$ vs. CC: $\mathrm{Q}=90.25$, d.f $=21, p<0.0001$, $\left.\mathrm{I}^{\wedge} 2=76.7 \%(65.1 \%-84.5 \%)\right]$, and [T vs. C allele: $\mathrm{Q}=$ 96.87, d.f $=18, p<0.0001, \mathrm{I}^{\wedge} 2=81.4 \%(71.9 \%-87.7 \%)$. To detect the sources of heterogeneity subgroup analyses by cancer type and ethnicity group were performed. In the subgroup analyses by cancer type heterogeneity was significantly reduced. The results suggested that the studies in prostate cancer, renal cell carcinoma, lung cancer, Caucasian ethnicity and Asian ethnicity were the main sources of heterogeneity (Additional file 1).

\section{Association of the HIF1A $1790 \mathrm{G} /$ A polymorphism with cancer risk}

The pooled ORs for overall cancer suggested that the HIF1A 1790 G/A polymorphism was significantly associated with increasing cancer risk for homozygote comparison [AA vs. GG: OR 5.10, 95 \% CI (3.12-8.33), p-value: $<0.0001$, heterozygote comparison [GA vs. GG: OR 1.74, $95 \%$ CI (1.20-2.52), $p$-value: 0.0033, dominant model [AA + GA vs. GG: OR 1.82, 95 \% CI (1.26-2.62), $p$-value: 0.0014], recessive model [AA vs. GA + GG: OR 3.79, $95 \%$ CI (2.34-6.15), $p$-value: $<0.0001]$ and [A vs. G allele: OR 1.82, 95 \% CI (1.31-2.52), $p$-value: 0.0003] (Fig. 3). 


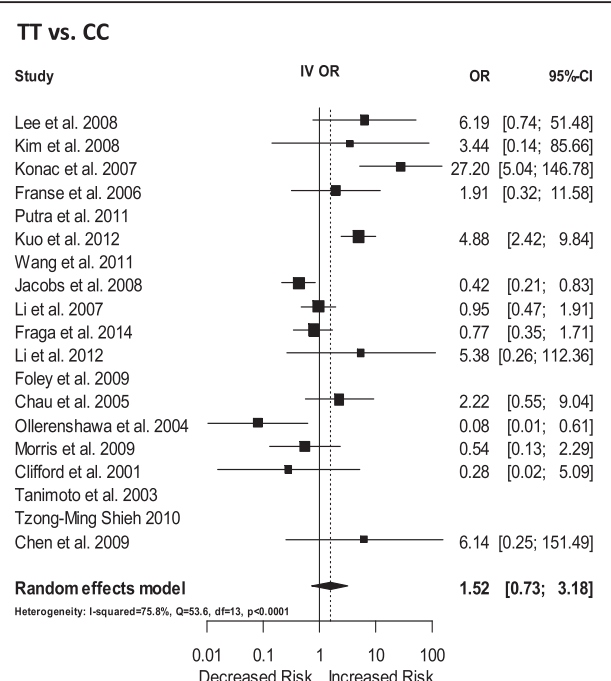

$\mathrm{TT}+\mathrm{CT}$ vs. CC

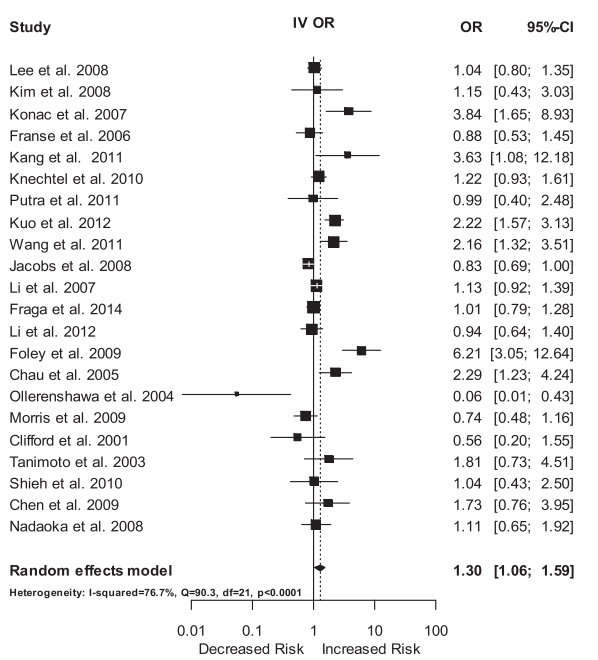

T allele vs. C allele

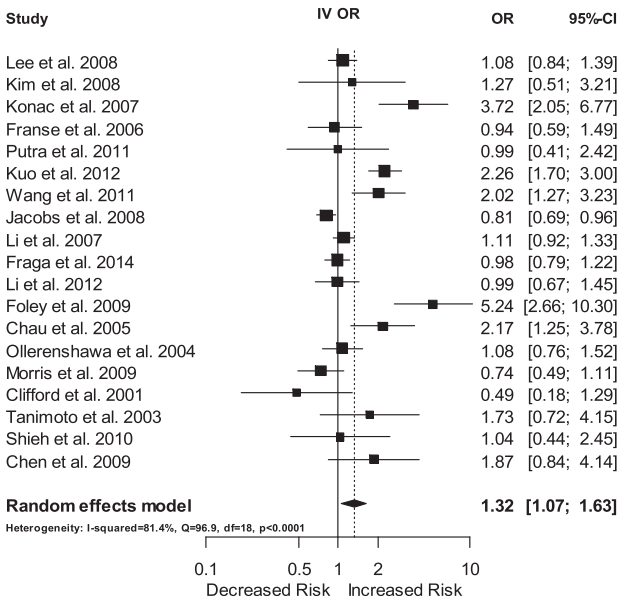

In Forest Plot: The squares and horizontal lines corresponds the individual study-specific ORs with 95\% $\mathrm{Cls}$. The black areas of the squares represent the corresponding study weight. The black diamond reflects the pooled OR and the lateral points of the diamonds represent the Confidence Intervals of the overall analyses. The solid vertical lines are the OR of 1 which is line of no effect. The dashed vertical lines show the corresponding pooled ORs of the analyses.
OR $\quad 95 \%-\mathrm{Cl}$

$1.00[0.77 ; 1.30]$ $1.02[0.38 ; 2.77$ $2.57[1.04 ; 6.36]$ $0.83[0.50 ; 1.39]$ $0.99[0.40 ; 2.48]$ $1.82[1.26 ; 2.63]$ $2.16[1.32 ; 3.51]$ $0.87[0.72 ; 1.05]$ $1.15[0.93 ; 1.42]$ $1.15[0.93 ; 1.42]$ $1.03[0.80 ; 1.32]$ $0.91[0.61 ; 1.35]$ $6.21[3.05 ; 12.64]$ $2.30[1.18 ; 4.51]$ $0.04[0.00 ; 0.29]$ $0.77[0.48 ; 1.21]$ $0.68[0.24 ; 1.91]$ $1.81[0.73 ; 4.51]$ $1.04[0.43 ; 2.50]$ $1.58[0.68 ; 3.67]$

$1.23[1.00 ; 1.53]$

TT vs. $\mathrm{CT}+\mathrm{CC}$

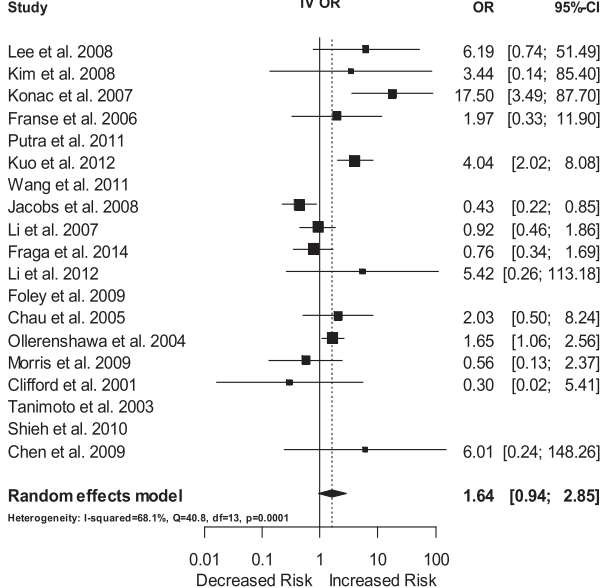

Fig. 2 Forest plot of HIF1A polymorphism $1772 \mathrm{C} / \mathrm{T}$ for overall cancer 
Table 3 Meta-analysis of the HIF1A 1772 C/T polymorphism association with cancer

\begin{tabular}{|c|c|c|c|c|c|c|c|c|c|c|c|c|}
\hline & \multirow[b]{2}{*}{ Study number } & \multirow[b]{2}{*}{ Sample size } & \multicolumn{2}{|l|}{ TT vs. CC } & \multicolumn{2}{|l|}{ CT vs. CC } & \multicolumn{2}{|l|}{$\pi+C T$ vs. $C C$} & \multicolumn{2}{|l|}{$\Pi$ vs. $C T+C C$} & \multicolumn{2}{|l|}{ T vs. C } \\
\hline & & & OR $(95 \% \mathrm{Cl})$ & $p$ value & OR $(95 \%$ Cl) & $p$ value & OR $(95 \%$ Cl) & $p$ value & OR $(95 \% \mathrm{Cl})$ & $p$ value & OR $(95 \% \mathrm{Cl})$ & $p$ value \\
\hline Overall cancer & 22 & 19024 & $1.52[0.73-3.18]$ & 0.2648 & $1.23[1.00-1.53]$ & 0.0536 & 1.30 [1.06-1.59] & 0.0115 & $1.64[0.94-2.85]$ & 0.0832 & 1.32 [1.07-1.63] & 0.0098 \\
\hline Prostate cancer & 6 & 8688 & $0.84[0.47-1.49]$ & 0.5449 & 1.34 [0.95-1.87] & 0.0913 & 1.33 [0.95-1.87] & 0.0982 & $0.81[0.47-1.40]$ & 0.4535 & $1.29[0.94-1.76]$ & 0.1178 \\
\hline Colorectal cancer & 3 & 3080 & $1.91[0.32-11.58]$ & 0.4801 & $0.83[0.50-1.39]$ & 0.4817 & $1.24[0.77-2.01]$ & 0.3756 & 1.97 [0.33-11.90] & 0.4603 & 0.94 [0.59-1.49] & 0.7833 \\
\hline Renal cancer & 3 & 1145 & $0.27[0.08-0.90]$ & 0.0335 & $0.40[0.12-1.34]$ & 0.1369 & $0.43[0.15-1.20]$ & 0.1082 & 1.08 [0.44-2.64] & 0.8703 & $0.84[0.58-1.22]$ & 0.3548 \\
\hline Breast cancer & 2 & 2893 & 5.18 [0.88-30.38] & 0.0683 & $1.00[0.77-1.29]$ & 0.9964 & $1.05[0.81-1.35]$ & 0.7221 & 5.18 [0.88-30.36] & 0.0684 & 1.09 [0.86-1.39] & 0.4701 \\
\hline Lung cancer & 2 & 778 & 4.88 [2.42-9.84] & $<0.0001$ & $1.56[0.94-2.61]$ & 0.088 & $1.67[0.79-3.54]$ & 0.1832 & 4.04 [2.02-8.08] & $<0.0001$ & $1.68[0.77-3.64]$ & 0.1908 \\
\hline OscC & 2 & 922 & $6.14[0.25-151.49]$ & 0.2673 & $1.29[0.70-2.37]$ & 0.4142 & $1.36[0.75-2.49]$ & 0.3127 & $6.01[0.24-148.26]$ & 0.2729 & $1.43[0.79-2.56]$ & 0.2348 \\
\hline Other cancers & 4 & 1518 & 27.20 [5.04-146.78] & 0.0001 & 2.16 [1.46-3.18] & 0.0056 & $1.92[1.17-3.14]$ & 0.0093 & $17.5[3.49-87.70]$ & 0.0005 & 2.42 [1.55-3.77] & $<0.0001$ \\
\hline \multicolumn{13}{|l|}{ Ethnicity } \\
\hline Caucasian & 8 & 6037 & $0.97[0.24-3.93]$ & 0.9654 & 1.09 [0.60-2.00] & 0.7751 & 1.19 [0.75-1.89] & 0.4528 & 1.48 [0.65-3.39] & 0.352 & 1.31 [0.84-2.06] & 0.237 \\
\hline Asian & 11 & 7450 & $4.98[2.66-9.31]$ & $<0.0001$ & $1.30[1.01-1.69$ & 0.0455 & 1.41 [1.08-1.84] & 0.0109 & 4.28 [2.31-7.95] & $<0.0001$ & 1.43 [1.07-1.90] & 0.0156 \\
\hline Mixed & 3 & 5537 & $0.82[0.36-1.87]$ & 0.6408 & 1.16 [1.00-1.65] & 0.4178 & 1.16 [0.79-1.70] & 0.4526 & $0.79[0.37-1.71]$ & 0.5544 & $1.14[0.78-1.67]$ & 0.505 \\
\hline
\end{tabular}




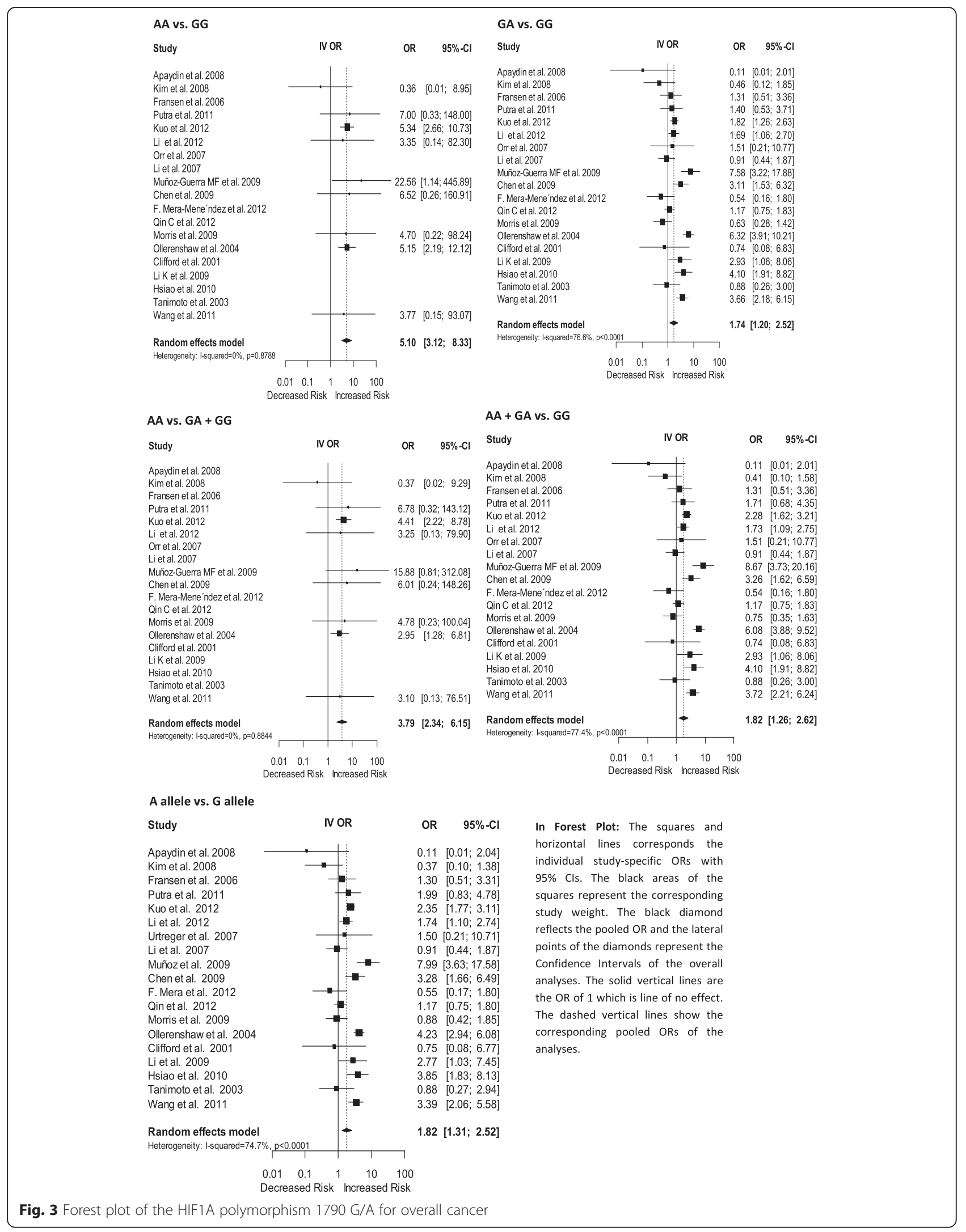




\section{Subgroup analyses by cancer type}

The analyzed data of prostate cancer suggested no significant association with the HIF1A 1790 G/A polymorphism. The subgroup analyses of renal cancer suggested that the HIF1A 1790 G/A polymorphism was significantly associated with increasing cancer risk for homozygote comparison [AA vs. GG: OR 5.11, 95 \% CI (2.24-11.66), $p$-value: 0.0001 ], recessive model [AA vs. GA + GG: OR 3.05, 95 \% CI (1.36-6.84), p-value: 0.0068] whereas the subgroup analyses of breast cancer showed that the HIF1A 1790 G/A polymorphism was significantly associated with decreasing cancer risk for [A vs. G allele: OR 0.30, $95 \%$ CI (0.09-1.00), $p$-value: 0.0495]. The subgroup analyses of lung cancer suggested that the HIF1A 1790 G/A polymorphism was significantly associated with increasing cancer risk for homozygote comparison [AA vs. GG: OR 5.41, 95 \% CI (2.74-10.69), $p$ value: $<0.0001$, heterozygote comparison [GA vs. GG: OR 1.76, 95 \% CI (1.25-2.49), p-value: 0.0013], dominant model [AA + GA vs. GG: OR 2.20, 95 \% CI (1.60-3.03), $p$-value: $<0.0001$ ], recessive model [AA vs. GA + GG: OR 4.51, $95 \%$ CI (2.31-8.81), $p$-value: $<0.0001$ ] and [A vs. G allele: OR 2.31, 95 \% CI (1.77-3.02), $p$-value: <0.0001]. Also, the subgroup analyses of oral squamous cell carcinoma (OSCC) suggested that the HIF1A 1790 G/A polymorphism was significantly associated with increasing cancer risk for homozygote comparison [AA vs. GG: OR 12.68, $95 \%$ CI (1.43-112.64), $p$-value: 0.0227], heterozygote comparison [GA vs. GG: OR 4.69, $95 \% \mathrm{CI}$ (1.96-11.21), $p$-value: 0.0005], dominant model [AA + GA vs. GG: OR 5.17, $95 \%$ CI (1.99-13.43), $p$-value: 0.0008 ], recessive model [AA vs. GA + GG: OR 10.12, $95 \%$ CI (1.14-89.72), p-value: 0.0376] and [A vs. G allele: OR 5.00, 95 \% CI (2.10-11.97), $p$-value: 0.0003] (Table 4). The subgroup analyses of Other Cancers suggested that the HIF1A $1790 \mathrm{G} / \mathrm{A}$ polymorphism is highly associated with increasing Other Cancer risk heterozygote comparison [GA vs. GG: OR 1.96, $95 \%$ CI (1.05-3.65), $p$-value: 0.0336], dominant model [AA + GA vs. GG: OR 1.96, $95 \%$ CI (1.05-3.67), $p$-value: 0.0341], and [A vs. G allele: OR 1.91, 95 \% CI (1.06-3.44), $p$-value: 0.0306] (Table 4).

\section{Subgroup analyses by ethnicity group}

For Caucasian population, the analyzed data suggested that the HIF1A 1790 G/A polymorphism was highly associated with increasing cancer risk for homozygote comparison [AA vs. GG: OR 5.68, 95 \% CI (2.57-12.58), $p$-value: $<0.0001$ ], recessive model [AA vs. GA + GG: OR 3.42, $95 \%$ CI (1.57-7.45), $p$-value: 0.002]. For the Asian population, the subgroup analyses of ethnicity group suggested that the HIF1A 1790 G/A polymorphism was highly associated with increasing cancer risk for homozygote comparison [AA vs. GG: OR 4.76, 95 \% CI (2.558.91), $p$-value: $<0.0001$ ], heterozygote comparison [GA vs.
GG: OR 1.94, 95 \% CI (1.38-2.72), $p$-value: 0.0001], dominant model [AA + GA vs. GG: OR 2.04, $95 \%$ CI (1.44-2.87), $p$-value: $<0.0001$ ], recessive model [AA vs. GA + GG: OR 4.05, $95 \%$ CI (2.18-7.51), $p$-value: $<0.0001]$ and [A vs. G allele: OR 2.03, $95 \%$ CI (1.46-2.81), $p$-value: $<0.0001$ ] (Table 4).

\section{Sources of heterogeneity}

There were significant heterogeneity observed in the analyses of HIF1A 1790G/A polymorphism for overall cancer heterozygote comparison [GA vs. GG: $\mathrm{Q}=77.05$, d.f $=18, p$-value: $<0.0001, \mathrm{I}^{\wedge} 2=76.6 \%(63.8 \%-84.9 \%)$, dominant model $[\mathrm{AA}+\mathrm{GA}$ vs. GG: $\mathrm{Q}=79.66$, d.f $=18$, $p$-value: $\left.<0.0001, \mathrm{I}^{\wedge} 2=77.4 \%(65.1 \%-85.4 \%)\right]$, and $[\mathrm{A}$ vs. $\mathrm{G}$ allele: $\mathrm{Q}=71.09$, d. $\mathrm{f}=18, p$-value: $<0.0001, \mathrm{I}^{\wedge} 2=$ $74.7 \%$ (60.4 \%-83.8 \%)]. To detect the sources of heterogeneity subgroup analyses by cancer type and ethnicity group were performed. The results suggested that the studies in renal cell carcinoma, oral squamous cell carcinoma (OSCC), Caucasian ethnicity and Asian ethnicity were the main sources of heterogeneity (Additional file 2).

\section{Publication bias}

To investigate the evidence of publication bias of the HIF1A $1772 \mathrm{C} / \mathrm{T}$ polymorphism for $\mathrm{T}$ versus $\mathrm{C}$ allele and HIF1A 1790 G/A polymorphism for G versus A allele funnel plot were used. The conventionally constructed funnel plot $(\log$ odds ratio $[\log (\mathrm{OR}]$ vs $1 /$ standard error, 1/se) of HIF1A polymorphism $1772 \mathrm{C} / \mathrm{T}$ for $\mathrm{T}$ vs. $\mathrm{C}$ allele suggested that there was evidence of publication bias (Fig. 4). Also the funnel plot of HIF1A polymorphism $1790 \mathrm{G} / \mathrm{A}$ for A vs. G allele suggested that there was evidence of publication bias (Fig. 4). However, the Egger's linear regression analyses suggested no evidence of significant publication bias in [ $\mathrm{T}$ vs $\mathrm{C}$ allele: $\mathrm{t}=1.83$, d.f $=17, p$-value 0.0847] for HIF1A $1772 \mathrm{C} /$ T polymorphism. Also, for HIF1A 1790 G/A polymorphism results showed no significant evidence of publication bias in [A vs $\mathrm{G}$ allele: $\mathrm{t}=-1.87$, d.f $=17, p$-value 0.0787] (Additional file 3).

\section{Sensitivity analysis}

Studies which were not in HWE were excluded to evaluate the stability of the acquired results. The statistical significance of the results was not shifted after omitting the studies which were not in HWE which confirmed the obtained results of the meta-analysis were stable and robust.

\section{Conclusion}

Results generated from this meta-analysis indicated that both $1772 \mathrm{C} / \mathrm{T}$ and $1790 \mathrm{G} / \mathrm{A}$ polymorphisms are significantly associated with increasing overall cancer risk. The subgroup analyses by cancer type showed that both $1772 \mathrm{C} /$ $\mathrm{T}$ and $1790 \mathrm{G} / \mathrm{A}$ polymorphisms have significant association 
Table 4 Meta-analysis of the HIF1A 1790 G/A polymorphism association with cancer

\begin{tabular}{|c|c|c|c|c|c|c|c|c|c|c|c|c|}
\hline & \multirow[b]{2}{*}{ Study number } & \multirow[b]{2}{*}{ Sample size } & \multicolumn{2}{|l|}{ AA vs. GG } & \multicolumn{2}{|l|}{ GA vs. GG } & \multicolumn{2}{|l|}{$A A$ vs. $G A+G G$} & \multicolumn{2}{|l|}{$A A+G A$ vs. GG } & \multicolumn{2}{|l|}{ A vs. G } \\
\hline & & & OR $(95 \% \mathrm{Cl})$ & $p$ value & OR $(95 \% \mathrm{Cl})$ & $p$ value & OR $(95 \% \mathrm{Cl})$ & $p$ value & OR $(95 \% \mathrm{Cl})$ & $p$ value & OR $(95 \% \mathrm{Cl})$ & $p$ value \\
\hline Overall & 19 & 10654 & $5.10[3.12-8.33]$ & $<0.0001$ & $1.74[1.20-2.52]$ & 0.0033 & $3.79[2.34-6.15]$ & $<0.0001$ & $1.82[1.26-2.62]$ & 0.0014 & $1.82[1.31-2.52]$ & 0.0003 \\
\hline Renal cancer & 4 & 2503 & $5.11[2.24-11.66]$ & 0.0001 & $1.51[0.45-5.05]$ & 0.5038 & $3.05[1.36-6.84]$ & 0.0068 & 1.58 [0.49-5.03] & 0.442 & 1.53 [0.60-3.92] & 0.3747 \\
\hline Prostate cancer & 3 & 4208 & $3.35[0.14-82.30]$ & 0.4597 & $1.41[0.96-2.08]$ & 0.0822 & $3.25[0.13-79.90]$ & 0.4707 & 1.41 [0.93-2.15] & 0.1043 & $1.42[0.93-2.17]$ & 0.1093 \\
\hline Breast cancer & 2 & 396 & $0.36[0.01-8.95]$ & 0.5332 & $0.35[0.10-1.24]$ & 0.1045 & 0.37 [0.02-9.29] & 0.5484 & $0.32[0.09-1.10]$ & 0.0702 & 0.30 [0.09-1.00] & 0.0495 \\
\hline Lung cancer & 2 & 778 & $5.41[2.74-10.69]$ & $<0.0001$ & $1.76[1.25-2.49]$ & 0.0013 & $4.51[2.31-8.81]$ & $<0.0001$ & $2.20[1.60-3.03]$ & $<0.0001$ & $2.31[1.77-3.02]$ & $<0.0001$ \\
\hline OsCC & 2 & 724 & $12.68[1.43-112.64]$ & 0.0227 & $4.69[1.96-11.21]$ & 0.0005 & 10.12 [1.14-89.72] & 0.0376 & 5.17 [1.99-13.43] & 0.0008 & 5.00 [2.10-11.97] & 0.0003 \\
\hline Other cancers & 6 & 2045 & 3.77 [0.15-93.07] & 0.4171 & $1.96[1.05-3.65]$ & 0.0336 & $3.10[0.13-76.51]$ & 0.4887 & $1.96[1.05-3.67]$ & 0.0341 & $1.91[1.06-3.44]$ & 0.0306 \\
\hline \multicolumn{13}{|l|}{ Ethnicity } \\
\hline Caucasian & 8 & 2666 & $5.68[2.57-12.58]$ & $<0.0001$ & $1.43[0.54-3.74]$ & 0.4691 & $3.42[1.57-7.45]$ & 0.002 & 1.50 [0.58-3.85] & 0.3987 & $1.52[0.68-3.42]$ & 0.3103 \\
\hline Asian & 10 & 4914 & $4.76[2.55-8.91]$ & $<0.0001$ & $1.94[1.38-2.72]$ & 0.0001 & $4.05[2.1-7.51]$ & $<0.0001$ & $2.04[1.44-2.87]$ & $<0.0001$ & $2.03[1.46-2.81]$ & $<0.0001$ \\
\hline
\end{tabular}




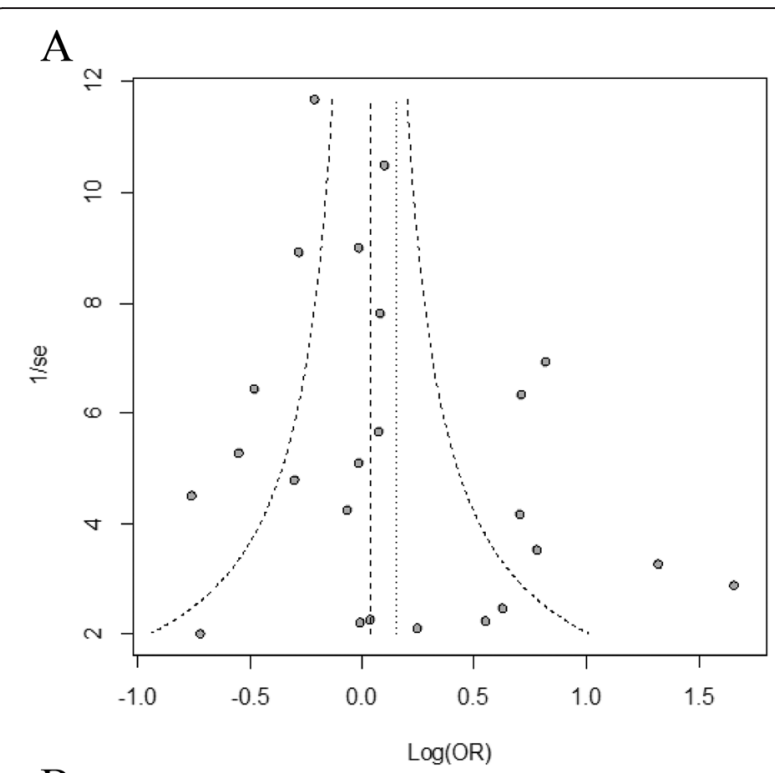

B

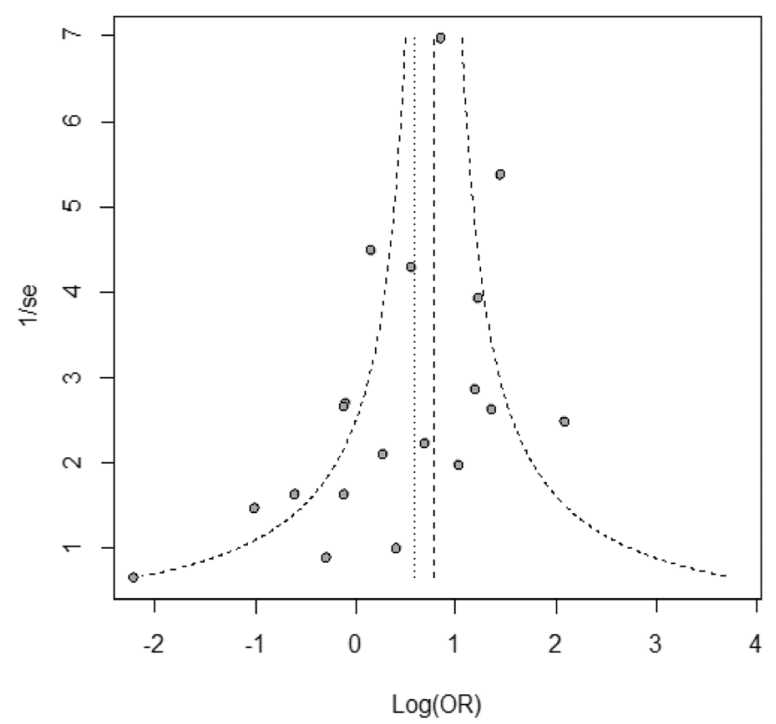

Fig. 4 Funnel plot of HIF1A polymorphism (a) $1772 \mathrm{C} / \mathrm{T}$ for $\mathrm{T}$ allele vs. C allele and (b) $1790 \mathrm{G} / \mathrm{A}$ for A allele vs. G allele; showing visual evidence of publication bias

with lung cancer, whereas these two polymorphisms showed no significant association with prostate cancer. In oral squamous cell carcinoma (OSCC) subgroup analyses data showed that only 1790 G/A polymorphism has significant association whereas the HIF1A $1772 \mathrm{C} / \mathrm{T}$ polymorphism showed no significant association. However, the $1772 \mathrm{C} / \mathrm{T}$ polymorphism has indicated significantly decreased risk in renal cell carcinoma. Also, 1790 G/A polymorphism has increased the cancer risk significantly in both Caucasian and Asian ethnicity. Taken together all analyzed data, HIF1A could be a prognostic marker useful for early detection and diagnosis for cancers. In future, further experimental validations would be necessary to confirm the results.

\section{Additional files}

\section{Additional file 1: Heterogeneity analysis of HIF1A $1772 \mathrm{C} / \mathrm{T}$. (XLSX $14 \mathrm{~kb}$ )}

Additional file 2: Heterogeneity analysis of A polymorphism/A. (XLSX $12 \mathrm{~kb}$ )

Additional file 3: Egger's linear regression analyses of HIF1A 1772 C/T and HIF1A $1790 \mathrm{G} / \mathrm{A}$. (DOCX $17 \mathrm{~kb}$ )

\section{Abbreviations}

GWAS: Genome wide association studies; SNP: Single nucleotide polymorphism; REM: Random effects model; Cl: Confidence interval; SE: Standard error; Log: Logarithm; HWE: Hardy-Weinberg Equilibrium; HIF1: Hypoxia- inducible factor -1; HIF1A: Hypoxia- inducible factor -1a; OR: Odds ratio; OSCC: Oral squamous cell carcinoma..

\section{Competing interests}

The authors declare that they have no competing interests.

\section{Authors' contributions}

Jesmin and $\mathrm{MBH}$ designed the research, $\mathrm{MBH}$ designed the experimental data analysis model and validate interpretation, MTA and Al collected, screened and analyzed the data. Jesmin, MBH and MTA analyzed and interpreted the result, drafted and revised the manuscript. All authors have read and approved the final manuscript.

\section{Acknowledgements}

This work was supported in part by NST Grant 39.012.002.01,03.021.2014-09/260 from the Ministry of Science \& Technology (MOST), Government of the People's Republic of Bangladesh (to Al and Jesmin).

\section{Author details}

${ }^{1}$ Department of Statistics, Biostatistics \& Informatics, University of Dhaka, Dhaka 1000, Bangladesh. ${ }^{2}$ Department of Genetic Engineering \& Biotechnology, University of Dhaka, Dhaka 1000, Bangladesh.

Received: 22 September 2015 Accepted: 18 December 2015 Published online: 29 December 2015

\section{References}

1. World Cancer Report. WHO|Cancer. 2014. (http://www.who.int/mediacentre/ factsheets/fs297/en/).

2. Jemal A, Siegel R, Ward E, Hao Y, Xu J, Thun MJ. Cancer statistics, 2009, CA Cancer. J Clin. 2009;59:225-49. doi:10.3322/caac.20006.

3. Yanh X, Zhu HC, Zhang C, Qin Q, Liu J, Xu LP, et al. HIF1A 1771 C/T and 1790 G/ A polymorphism are significantly associated with higher cancer risk: an updated Meta-analysis from 34 case-control studies. Plos one. 2013:8(11):e80396.

4. Hill RP, Marie-Egyptienne DT, Hedley DW. Cancer stem cells, hypoxia and metastasis. Semin Radient Oncol. 2009;19:106-11. doi:10.1016/j.semradonc. 2008.12.002

5. Huang Y, Lorenzo AD, Jiang W, Cantalupo A, Sessa WC, Giordano FJ. HIF-1a in vascular smooth muscle regulates blood pressure homeostasis through a PPARYangiotensin II receptor type 1 (ATR1) axis. Hypertension. 2013;62(3):634-40.

6. Shastry BS. SNP alleles in human disease and evolution. J Hum Genet. 2002;47:561-6.

7. Ke Q, Costa M. Hypoxia-inducible factor-1 (HIF-1). Mol Pharmacol. 2006;70:1469-80.

8. Clifford SC, Astuti D, Hooper L, Maxwell PH, Ratcliffe PJ, Maher ER. The PVHL-associated SCF ubiquitin ligase complex: molecular genetic analysis of elongin B and C, Rbx1 and HIF-1alpha in renal cell carcinoma. Oncogene. 2001;20(36):5067-74. PMID 11526493.

9. Tanimoto K, Yoshiga K, Eguchi H, Kaneyasu M, Ukon K, Kumazaki T, et al. Hypoxia-inducible factor-1alpha polymorphisms associated with enhanced transactivation capacity, implying clinical significance. Carcinogenesis. 2003;24(11):1779-8. PMID 12919954.

10. Ollerenshaw M, Page T, Hammonds J, Demaine A. Polymorphisms in the hypoxia inducible factor-1alpha gene (HIF1A) are associated with the renal cell carcinoma phenotype. Cancer Genet Cytoenet. 2004;153(2):122-6. PMID 15350301. 
11. Chau CH, Permenter MG, Steinberg SM, Retter AS, Dahut WL, Price DK, et al. Polymorphism in the hypoxia-inducible factor 1alpha gene may confer susceptibility to androgen-independent prostate cancer. Cancer Biol Ther. 2005:4(11):1222-5. PMID 16205110.

12. Fransén $K$, Fenech $M$, Fredrikson M, Dabrosin C, Söderkvist P. Association between ulcerative growth and hypoxia inducible factor-1alpha polymorphisms in colorectal cancer patients. Mol Carcinog. 2006;45(11):833-40. PMID 16865676.

13. Konac E, Onen HI, Metindir J, Alp E, Biri AA, Ekmekci A. An investigation of relationships between hypoxia-inducible factor-1 alpha gene polymorphisms and ovarian, cervical and endometrial cancers. Cancer Detect Prev. 2007;31(1):102-9. PMID 17418979.

14. Li H, Bubley GJ, Balk SP, Gaziano JM, Pollak M, Stampfer MJ. Hypoxiainducible factor-1alpha (HIF-1alpha) gene polymorphisms, circulating insulin-like growth factor binding protein (IGFBP)-3 levels and prostate cancer. Prostate. 2007;67(12):1354-61. PMID 17624927.

15. Lee JY, Choi JY, Lee KM, Park SK, Han SH, Noh DY, et al. Rare variant of hypoxia-inducible factor-1alpha (HIF-1A) and breast cancer risk in Korean women. Clin Chim Acta. 2008;389(1-2):167-70. PMID 18160046.

16. Kim HO, Jo YH, Lee J, Lee SS, Yoon KS. The C1772T genetic polymorphism in human HIF-1alpha gene associates with expression of HIF-1alpha protein in breast cancer. Oncol Rep. 2008;20(5):1181-7. PMID 18949419.

17. Nadaoka J, Horikawa Y, Saito M, Kumazawa T, Inoue T, Narita S, et al. Prognostic significance of HIF-1 alpha polymorphisms in transitional cell carcinoma of the bladder. Int J Cancer. 2008;122(6):1297-302. PMID 18000826.

18. Jacobs EJ, Hsing AW, Bain EB, Stevens VL, Wang Y, Chen J, et al. Polymorphisms in angiogenesis-related genes and prostate cancer. Cancer Epidemiol Biomarkers Prev. 2008:17(4):972-7. PMID 18398039.

19. Foley $R$, Marignol $L$, Thomas AZ, Cullen IM, Perry AS, Tewari $P$, et al. The HIF-1alpha C1772T polymorphism may be associated with susceptibility to clinically localised prostate cancer but not with elevated expression of hypoxic biomarkers. Cancer Biol. 2009;8(2):118-24. PMID 19106642.

20. Morris MR, Hughes DJ, Tian YM, Ricketts CJ, Lau KW, Gentle D. Mutation analysis of hypoxia-inducible factors HIF1A and HIF2A in renal cell carcinoma. Anticancer Res. 2009;29(11):4337-43. PMID 20032376.

21. Chen MK, Chiou HL, Su SC, Chung TT, Tseng HC, Tsai HT, et al. The association between hypoxia inducible factor-1alpha gene polymorphisms and increased susceptibility to oral cancer. Oral Oncol. 2009;45(12):e222-6. PMID 19717330.

22. Shieh TM, Chang KW, Tu HF, Shih YH, Ko SY, Chen YC, et al. Association between the polymorphisms in exon 12 of hypoxia-inducible factor-1alpha and the clinic-pathological features of oral squamous cell carcinoma. Oral Oncol. 2010;46(9):e47-53. PMID 20656543

23. Knechtel G, Szkandera J, Stotz M, Hofmann G, Langsenlehner U, Krippl P, et al Single nucleotide polymorphisms in the hypoxia-inducible factor-1 gene and colorectal cancer risk. Mol Carcinog. 2010;49(9):805-9. PMID 20572162.

24. Kang MJ, Jung SA, Jung JM, Kim SE, Jung HK, Kim TH, et al. Associations between single nucleotide polymorphisms of MMP2, VEGF, and HIF1A genes and the risk of developing colorectal cancer. Anticancer Res. 2011;31(2):575-84. PMID 21378341.

25. Putra AC, Tanimoto K, Arifin M, Hiyama K. Hypoxia-inducible factor-1a polymorphisms are associated with genetic aberrations in lung cancer. Respirology. 2011;16(5):796-802. PMID 21435097.

26. Wang X, Liu Y, Ren H, Yuan Z, Li S, Sheng J, et al. Polymorphisms in the hypoxia-inducible factor-1a gene confer susceptibility to pancreatic cancer. Cancer Biol Ther. 2011;12(5):383-7. PMID 21709439.

27. Kuo WH, Shih CM, Lin CW, Cheng WE, Chen SC, Chen W, et al. Association of hypoxia inducible factor-1a polymorphisms with susceptibility to nonsmall-cell lung cancer. Transl Res. 2012;159(1):42-50. PMID 22153809.

28. Li P, Cao Q, Shao PF, Cai HZ, Zhou H, Chen JW, et al. Genetic polymorphisms in HIF1A are associated with prostate cancer risk in a Chinese population. PMID 23042446 Asian J Androl. 2012;14(6):864-9. PMID 23042446.

29. Fraga A, Ribeiro R, Príncipe P, Lobato C, Pina F, Maurício J, et al. The HIF1A functional genetic polymorphism at locus +1772 associates with progression to metastatic prostate cancer and refractoriness to hormonal castration. Eur J Cancer. 2014:50(2):359-65. PMID 24090974.

30. Orr-Urtreger A, Bar-Shira A, Matzkin H, Mabjeesh NJ. The homozygous P582S mutation in the oxygen-dependent degradation domain of HIF-1 alpha is associated with increased risk for prostate cancer. Prostate. 2007;67(1):8-13. PMID 16998808.

31. Apaydin I, Konac E, Onen HI, Akbaba M, Tekin E, Ekmekci A. Single nucleotide polymorphisms in the hypoxia-inducible factor-1alpha (HIF-1alpha) gene in human sporadic breast cancer. Arch Med Res. 2008;39(3):338-45. PMID 18279708
32. Muñoz-Guerra MF, Fernández-Contreras ME, Moreno AL, Martín ID, Herráez B, Gamallo C. Polymorphisms in the hypoxia inducible factor 1-alpha and the impact on the prognosis of early stages of oral cancer. Ann Surg Oncol. 2009;16(8):2351-8. PMID 19449077.

33. Li K, Zhang Y, Dan Z, Wang Y, Ren ZC. Association of the hypoxia inducible factor-1-alpha gene polymorphisms with gastric cancer in Tibetans. Biochem Genet. 2009:47(9-10):625-34. PMID 19504235.

34. Hsiao PC, Chen MK, Su SC, Ueng KC, Chen YC, Hsieh YH, et al. Hypoxia inducible factor-1alpha gene polymorphism G1790A and its interaction with tobacco and alcohol consumptions increase susceptibility to hepatocellular carcinoma. J Surg Oncol. 2010;102(2):163-9. PMID 20648588.

35. Mera-Menéndez F, Hinojar-Gutiérrez A, Guijarro Rojas M, de Gregorio JG, Mera-Menéndez E, Sánchez JJ, et al. Polymorphisms in HIF-1alpha affect presence of lymph node metastasis and can influence tumor size in squamous-cell carcinoma of the glottic larynx. Clin Transl Oncol. 2013; 15(5):358-63. PMID 22914908.

36. Qin C, Cao Q, Ju X, Wang M, Meng X, Zhu J, et al. The polymorphisms in the VHL and HIF1A genes are associated with the prognosis but not the development of renal cell carcinoma. Ann Oncol. 2012;23(4):981-9. PMID 21778301.

37. Hu X, Fang Y, Zheng J, He Y, Zan X, Lin S, et al. The association between HIF-1a polymorphism and cancer risk: a systematic review and metaanalysis. Tumor Biol. 2014;35:903-16. PMID:24046090.

38. Yan Q, Chen P, Wang S, Liu N, Zhao P, Gu A. Association between HIF-1a C1772T/G1790A polymorphisms and cancer susceptibility: an updated systematic review and meta-analysis based on 40 case-control studies. BMC Cancer. 2014:14:950. PMID:25496056.

39. Liberati A, Altman DG, Tetzlaff J, Mulrow C, Gøtzsche PC, loannidis JP, et al. The PRISMA statement for reporting systemic reviews and meta-analyses of studies that evaluate health care interventions: explanation and elaboration. Ann Intern Med. 2009;151:W-65-94.

40. Liu IM, Agresti A. Mantel-Haenszel-type inference for cumulative odds ratios with a stratified ordinal response. Biometrics. 1996;52(4):1223-34.

41. Sutton AJ, Abrams KR, Jones DR, Sheldon TA, Song F. Methods for Metaanalysis in medical research. Chichester: John Wiley; 2000.

42. Cochran WG. The combination of estimates from different experiments. Biometrics. 1954;10:101-29.

43. Higgins JPT, Thompson SG. Quantifying heterogeneity in a meta-analysis. Stat Med. 2002;21:1539-58.

44. Light RJ, Pillemar DG. Summing Up: The science of Reviewing Research. Cambridge, MA: Harvard University Press; 1984.

45. Egger M, Smith GD, Schneider M, Minder C. Bias in meta-analysis detected by a simple, graphical test. BMJ. 1997;315(7109):629-4. doi:10.1136/bmj.315. 7109.629.PMC2127453.

46. Zhao J. H. Gap: Genetic Analysis Package. R package version 1.1-12, 2014. http://cran.r-project.org/web/packages/gap/index.htmlFoundation for statistical computing (2008). R: a language and environment for statistical computing. Version 2.8.0. Vienna.

47. Zhao JH. Gap: genetic analysis package. J of Stat Software. 2007;23(8):1-18. http://www.jstatsoft.org/v23/i08.

\section{Submit your next manuscript to BioMed Central and we will help you at every step:}

- We accept pre-submission inquiries

- Our selector tool helps you to find the most relevant journal

- We provide round the clock customer support

- Convenient online submission

- Thorough peer review

- Inclusion in PubMed and all major indexing services

- Maximum visibility for your research

Submit your manuscript at www.biomedcentral.com/submit
Biomed Central 